\title{
Impact of $\gamma$-irradiation, ageing and their interactions on multilayer films followed by AComDim
}

\author{
Fanny Gaston ${ }^{\text {a, b, d, * }}$, Nathalie Dupuy a , Sylvain R.A. Marque ${ }^{\text {b, c }}$, Magali Barbaroux ${ }^{\text {d }}$, \\ Samuel Dorey ${ }^{\mathrm{d}, * *}$ \\ a Aix Marseille Univ, CNRS, IRD, Avignon Université, IMBE UMR 7263, 13397, Marseille, France \\ ${ }^{\mathrm{b}}$ Aix Marseille Univ, CNRS, ICR, Case 551, 13397 Marseille Cedex 20, France \\ c Vorozhtsov Novosibirsk Institute of Organic Chemistry Office 312, 9 Prospect Academican Laurentiev, 630090 Novosibirsk, Russia \\ d Sartorius Stedim FMT S.A.S, Z.I. Les Paluds, Avenue de Jouques CS91051, 13781 Aubagne Cedex, France
}

Keywords:

$\gamma$-irradiation

Polyethylene

Ethylene vinyl acetate

FTIR spectra

AComDim
G R A P H I C A L A B S T R A C T

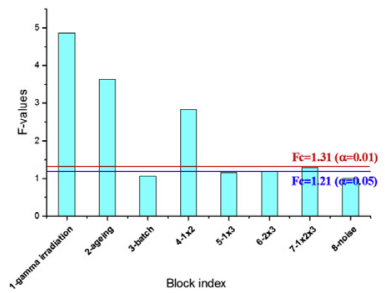

\begin{tabular}{c|c|c}
\multicolumn{3}{|c}{ Influential factors } \\
\hline Factor 1 & $\gamma$-dose & $\checkmark$ \\
\hline Factor 2 & natural ageing & $\checkmark$ \\
\hline Factor 3 & batch & $\mathbf{\times}$ \\
\hline Factor 4 & $\gamma$-dose $\times$ natural ageing & $\checkmark$ \\
\hline Factor 5 & $\gamma$-dose $\times$ batch & $\times$ \\
\hline Factor 6 & natural ageing $\times$ batch & $\times$ \\
\hline Factor 7 & $\gamma$-dose $\times$ natural ageing $\times$ batch & $\times$ \\
\hline Factor 8 & noise & $\times$ \\
\hline
\end{tabular}

A B S T R A C T

To highlight the main factors involved in the degradation of polymers in multilayer films under $\gamma$ irradiation, the ANOVA Common Dimensions (AComDim, Analysis of Variance in Common Dimensions) method is applied on spectra recorded with ATR-FTIR (Attenuated Total Reflection-Fourier Transform Infrared). The present study focuses on the stability of $\gamma$-irradiated polymers used in single-use plastic bags made of multilayer films for the biopharmaceutical and biotechnological industries. The samples are irradiated at several $\gamma$-doses, up to $270 \mathrm{kGy}$, and compared with a non-irradiated sample used as reference. It shows that the $\gamma$-dose, the natural ageing up to six months and the $\gamma$-dose $\times$ ageing interaction are the most influential factors.

\section{Introduction}

The effect of irradiation on multi-layer polymer films is usually independently analyzed parameter by parameter (e.g. $\gamma$-irradiation doses, ageing, batches, etc) with independent analytical tools [1-10]. For a number of various uses (storage, mixing, freezing, transportation, formulation, and filling) biopharmaceutical 
solutions are stored in sterile single-use plastic bags. The classical $\gamma$-irradiation dose range used for biopharmaceutical industries is between 25 and $45 \mathrm{kGy}$ [11], according to the regulation. The major advantage of radio-sterilization is the penetration power of the $\gamma$ radiation. Unfortunately, this process can induce modifications in the materials, as reported in the literature [12], while package integrity and security are due to appropriate flexible and barrier polymeric materials such as polyethylene and polyethylene-covinyl alcohol, respectively [13]. $\gamma$-sterilization of single-use systems initiates chemical reactions [14] and complex modifications inside the plastic material, leading to either an increase or a decrease in the molecular weight of polymers $[15,16]$ as well as to modifications of the additives or damage to the polymers themselves [17-19]. However the impact of the $\gamma$-irradiation of polymer is weak below $300 \mathrm{kGy}$ [20-23]. In this study, $\gamma$-irradiation doses investigated are up to $270 \mathrm{kGy}$ in order to emphazise the $\gamma$-irradiation effect and to better investigate the modifications on multilayer films. This study is a part of a global investigation on $\gamma$ irradiation on multilayer films. Several approaches were used to study the impact of $\gamma$-irradiation on multilayer films, such as ESR (Electron Spin Resonnance) [14] to observe the radicals formation, ATR-FTIR (Attenuated Total Reflection-Fourier Transform Infrared) $[24,25]$ and Raman spectroscopies to observe the structural modifications, the measurement of yellowing, the measurement of $\mathrm{O}_{2}$ transmission rate $\left(\mathrm{O}_{2} \mathrm{TR}\right)$ and water vapor transmission rate (WVTR), the measurement of $\mathrm{pH}$ to follow the acidity change of solution contained in the bag and the mecanical test to evaluate the robustness of film.

In this present paper, we analyze the changes in the FTIR spectra using ANOVA (ANalysis Of VAriance) Common Dimensions (AComDim) [26] to identify variations in the signals due to the effect of $\gamma$-irradiation doses, of ageing and of film batches. The AComDim method allows highlighting the influential factors $(\gamma$ doses, ageing and film batches) and their interactions by a simultaneous analysis of all data. The AComDim is a multi-block analysis, based on the same concept as ANOVA-PCA (also called APCA) and its description can be found in the papers by Amat et al. [27] and Bouveress et al. [26]. The AComDim method decomposes the experimental data matrix into successive matrices (also called mean matrices) containing the average at each level for each factor or interaction. The residuals matrix remaining after successive subtraction of all mean matrices is added back to each of them to obtain means plus residuals matrices (called blocks). Then, a multiblock PCA of all matrices is performed in order to extract its first principal component, or the "Common Components" (CCs). Each block provides a specific contribution (i.e. a specific weight), called salience, to the definition of each common component. Since all blocks contain a contribution from the residual matrix, the first Common Component CC1 (with higher saliences) contains mainly noise. The outputs of the AComDim method indicate whether variations in the data from different values relative to the change between two levels of a factor are significantly greater than the residual variability, and thus meaningful. Although the chemical ageing of polymer materials during irradiation has been widely studied in the literature, there are few reports on $\gamma$-irradiation influence emphasized up to $270 \mathrm{kGy}$ and ageing up to six months of multilayer films using a statistical approach, as the study presented in this article. The loading of the Common Components (CCs) provides information to discuss the spectral modifications associated with each factor or with the factor interactions. They also enable us to check whether the structural changes have generated chemical species. In our work, we are focused on the effects of $\gamma$ irradiation on the solid state of two 3-layer polymer films made of $\mathrm{PE} / \mathrm{EVOH} / \mathrm{PE}$ and EVA/EVOH/EVA from different batches. The $\gamma-$ irradiation impact and the subsequent ageing effect of polymers have been investigated through design of experiments with a full factorial design. The responses to the full factorial design are the spectroscopic data collected during experiments.

\section{Materials and methods}

\subsection{Film samples}

The two 3-layer webs studied in this work are: PE film and EVA film. The PE film has the following structure: PE/EVOH/PE, with a thickness of about $400 \mu \mathrm{m}$. The EVA film sample is composed of ethylene vinyl acetate (EVA) and ethylene vinyl alcohol (EVOH): EVA/EVOH/EVA, with a thickness of about $360 \mu \mathrm{m}$.

The different layers of these films contain additives including typically antioxidants (especially phenol and phosphite) and antiblocking agents. The addititive package concentration is typically $500-1000 \mathrm{ppm}$ in polyolefins, which is hence undetectable with ATR-FTIR. The additives are added during the films manufacture for their stabilization during the process as well as during their shelf life. Only the internal layer, which is in contact with the solution in future applications, is investigated in this study. Four batches of PE film and three batches of EVA film are investigated.

\section{2. $\gamma$-irradiation}

All film samples of PE and EVA films have been prepared in specific packaging (PE) to be irradiated at room temperature in a ${ }^{60} \mathrm{Co} \gamma$-source providing a dose rate of $8-13 \mathrm{kGy} / \mathrm{h}$, as given by Synergy Health company (Marseille, France). The samples have been $\gamma$-irradiated at doses of $30( \pm 1), 50( \pm 1), 115( \pm 2)$ and $270( \pm 5)$ $\mathrm{kGy}$. A sterilization cycle corresponds approximately to $25-30 \mathrm{kGy}$. To obtain the desired dose, it is necessary to perform several sterilization cycles, including a waiting time in non controlled storage conditions between each cycle. The samples are analyzed for the first time about 10 days after $\gamma$-irradiation. The impact of the $\gamma$ irradiation is assessed from modifications occurring between irradiated samples and non-sterilized amples, which correspond to $0 \mathrm{kGy}$ samples in the document. As modifications are expected to be weak, $\gamma$-irradiation doses are investigated up to $270 \mathrm{kGy}$ to force the $\gamma$-irradiation induced modifications and to better observe them.

\subsection{Mid-Fourier transform infrared (Mid-FTIR) spectroscopy}

The spectra are recorded with a Bruker "Golden Gate" attenuated total reflectance accessory provided with a diamond crystal. ATR-FTIR spectra of film samples are recorded from 4000 to $650 \mathrm{~cm}^{-1}$ (field of mid-infrared), with $4 \mathrm{~cm}^{-1}$ resolution and 64 scans, using a Thermo Nicolet Avatar spectrometer equipped with a MCT/A detector, an Ever-Glo source, and a $\mathrm{KBr} /$ germanium beam splitter. Three or five spectra are recorded for each sample to reduce the possible impact of the film inhomogeneity. Moreover, this study is conducted over several months; recordings are performed up to 6 months after $\gamma$-irradiation. All time point measurements have been recorded with a variability of \pm 2 days.

\subsection{Design of experiment}

\subsection{1. $P E$}

The PE spectra were used as responses in full-factorial experimental design built taking into account the different levels of the factors. The full-factorial design investigated one five-level factors for " $\gamma$-dose", one seven-level factor (for "ageing conditions") and one four-level factor (for batch) and included $5^{*} 7^{*} 4=140$ experiments (excluding center points). FTIR spectra were recorded at least 
3 times and sometimes up to 5 times. These full-factorial designs were balanced, i.e., the number of experiments was 476 . The illustration of design of experiments is displayed in Table 1.

\subsubsection{EVA}

The EVA spectra were used as responses in full-factorial experimental design built taking into account the different levels of the factors. The full-factorial design investigated one five-level factors for " $\gamma$-dose", one seven-level factor (for "ageing conditions") and one three-level factor (for batch) and included $5 * 7 * 3=105$ experiments (excluding center points). FTIR spectra were recorded at least twice and sometimes up to 5 times. These full-factorial designs were balanced, i.e., the number of experiments was 293. The same design of experiments was followed (Table 1).

\subsection{AComDim}

The Common Components and Specific Weights Analysis method, or ComDim, was developed to simultaneously consider multiple sets of matrices with different variables describing the same samples [28-30]. One such multi-block technique is "Common Component and Specific Weights Analysis", with the abbreviation CCSWA [31]. Historically, this method was developed to analyze tables as part of sensory assessment [32-34]. These methods may be useful in chemometrics to combine information about the same set of samples analyzed using different techniques (FTIR spectroscopy, Raman spectroscopy, XPS spectroscopy, ESR, physico-chemical analyses, etc.). The multi-block analysis methods aim at describing $\mathrm{p}$ data blocks observed for the same $\mathrm{n}$ samples (i.e. a set of $\mathrm{p}$ data matrices $\left(\mathrm{X}_{\mathrm{i}}, \mathrm{i}=1\right.$ to $\mathrm{p}$ ) each with $\mathrm{n}$ rows, but not automatically with the same number of variables) [26]. ComDim determines a common space describing the dispersion of all the data blocks. Each block has a specific weight (or 'salience') associated with each dimension in this common space. This is done by finding the directions describing common distributions of the samples in the spaces defined by the different data blocks. This explains then the name Common Component, abbreviated CC or Common Dimension, abbreviated CD. Salience points out the ranking of each block in the construction of the common dimension, and a "percentage of variability extracted" by each dimension can be computed. Significant differences in the values of saliences for a given dimension reflect then the fact that the dimension contains different amounts of information coming from each block [35].

AComDim, as an extension of ComDim used to analyze a set of blocks calculated from a single initial data matrix, aims thus at replacing any separate PCAs performed in the ANOVA-PCA method [36], also abbreviated APCA, by a single analysis using ComDim. The AComDim (Anova Common dimension) method allows

Table 1

Part of design of experiments.

\begin{tabular}{lll}
\hline Dose & Ageing time & Batch \\
\hline $0 \mathrm{kGy}$ & t0 & 1 \\
$30 \mathrm{kGy}$ & $\mathrm{t} 0$ & 1 \\
$50 \mathrm{kGy}$ & $\mathrm{t} 0$ & 1 \\
$115 \mathrm{kGy}$ & $\mathrm{t} 0$ & 1 \\
$270 \mathrm{kGy}$ & $\mathrm{t} 0$ & 1 \\
$0 \mathrm{kGy}$ & $\mathrm{t} 1 \mathrm{~m}$ & 1 \\
$30 \mathrm{kGy}$ & $\mathrm{t} 1 \mathrm{~m}$ & 1 \\
$50 \mathrm{kGy}$ & $\mathrm{t} 1 \mathrm{~m}$ & 1 \\
$115 \mathrm{kGy}$ & $\mathrm{t} 1 \mathrm{~m}$ & 1 \\
$270 \mathrm{kGy}$ & $\mathrm{t} 1 \mathrm{~m}$ & 1 \\
$0 \mathrm{kGy}$ & $\mathrm{t} 2 \mathrm{~m}$ & 1 \\
$\ldots$ & $\ldots$ & $\ldots$ \\
\hline
\end{tabular}

highlighting the influential factors ( $\gamma$-doses, ageing, film batches) and their interactions by a simultaneous analysis of all data $[27,34,37]$. In this case, the various factor matrices and interaction matrices calculated from the initial data matrix are all analyzed simultaneously, resulting in a series of Common Components. The samples are consequently distributed along all the Common Components, each associated with a vector of saliences reflecting the importance of the contribution of each data block to the corresponding Common Component. A preliminary stage consists in building $\mathrm{X}$ matrices by using the levels of the various factors stemming from the experimental design.

The following procedure calculates iteratively a series of score vectors for each successive common dimension. The score vectors are the coordinates of the $\mathrm{n}$ samples along the direction defined by a common dimension. According to Fig. 1, the algorithm can be detailed step-by-step [35,38]:

Step 1: for each table $\mathrm{X}_{\mathrm{i}}(\mathrm{n} \times \mathrm{k}$ ) each block is centered and each value is divided by the block norm, leading to the matrices $\mathrm{X}_{\mathrm{S}}(\mathrm{n} \mathrm{x}$ $\mathrm{k})$.

Step 2: a cycle for the calculation of the common component is initiated by iteration. The matrix $\mathrm{W}_{\mathrm{i}}=\mathrm{X}_{\mathrm{i}} \mathrm{X}_{\mathrm{i}}^{\mathrm{T}}$ of size $\mathrm{N}^{*} \mathrm{~N}$ is calculated for each block, where $X_{i}^{T}$ is the transpose matrix, leading to the matrix $\mathrm{W}_{\mathrm{i}}$.

Step 3: each matrix $W_{i}$ is multiplied by its salience (or weight) $\lambda_{i}$ (for the first iteration, all $\lambda_{i}=1$ ). Then the sum of the matrix results is done, element by element, to give the global matrix $\mathrm{W}_{\mathrm{G}}$.

Step 4: a PCA is done on $\mathrm{W}_{\mathrm{G}}$ to calculate the common dimension. This common dimension is given for the factorial coordinates $U_{W}$ of the samples of the first principal component of the $\mathrm{W}_{\mathrm{G}}$, with the vector q ( $\mathrm{nx} 1)$.

Step 5: recalculate the saliences $\lambda_{i}$ by pre- and post-multiplying each matrix $\mathrm{W}_{\mathrm{i}}$ by the vector $\mathrm{q}$. The calculation of $\mathrm{W}_{\mathrm{G}}$ and $\mathrm{q}$ are reiterated until convergence, at which point the scores of the first Common Component and the corresponding saliences of all the blocks have been calculated. It is worth noting if the correlations between $\mathrm{q}$ and the columns of $\mathrm{W}$ are high, its salience (weight) $\lambda$ will be high as well.

Step 6: To know if the calculations of the weights (salience) is finished (convergence), one calculates a quantity "Dif" of each iteration. Having defined a threshold, if Dif $_{\mathrm{n}}$ is obtained:

$\mathrm{Dif}_{\mathrm{n}}^{2}-\mathrm{Dif}_{\mathrm{n}-1}^{2}>$ threshold, the cycle goes on and $\lambda_{\mathrm{X}} . \mathrm{W}_{\mathrm{X}}$ is calculated once again (the step 3 is then calculated in the cycle). The matrices I are identity matrices.

Step 7: however, when $\mathrm{Dif}_{\mathrm{n}}^{2}-\mathrm{Dif}_{\mathrm{n}-1}^{2}<$ threshold, the calculation of the first component is finished and the vector $q$ is kept as well as the weights (salience) $\lambda_{X}$ for each matrix $X$ in that common dimension.

Step 8: the matrix $\mathrm{X}_{\mathrm{s}}$ is recalculated from an identity matrix I ( $\mathrm{n}$ $\mathrm{x} \mathrm{n}$ ), the vector q, and the former matrix $X_{s}$. Everything is repeated from the beginning for the second common component. Once the first CC calculated, the matrices $\mathrm{X}_{\mathrm{i}}$ are all deflated and the process repeated until the required number of $\mathrm{CC}$ extracted. The number of common components is defined as the number of factors + their interactions + the noise (common component). In that present study, there are 3 factors (i.e. $1,2,3), 4$ interactions $(1 * 2,1 * 3,2 * 3$, $1 * 2 * 3$ ) and the noise, that is to say $3+4+1=8$ components. The factors and their interactions are listed in Table 2.

All computations were performed using Matlab 7.14 (R2012a). The AComDim procedure was adapted from the ComDim function in the free toolbox SAISIR [39]. The code (Matlab) of the ComDim (CCSWA) method and examples of applications, are available on the web of the French group of chemometrics: http://www. chimiometrie.fr/comdim.html.

By examining the calculated saliences, it is possible to determine which Common Component is related to which factor. A great 


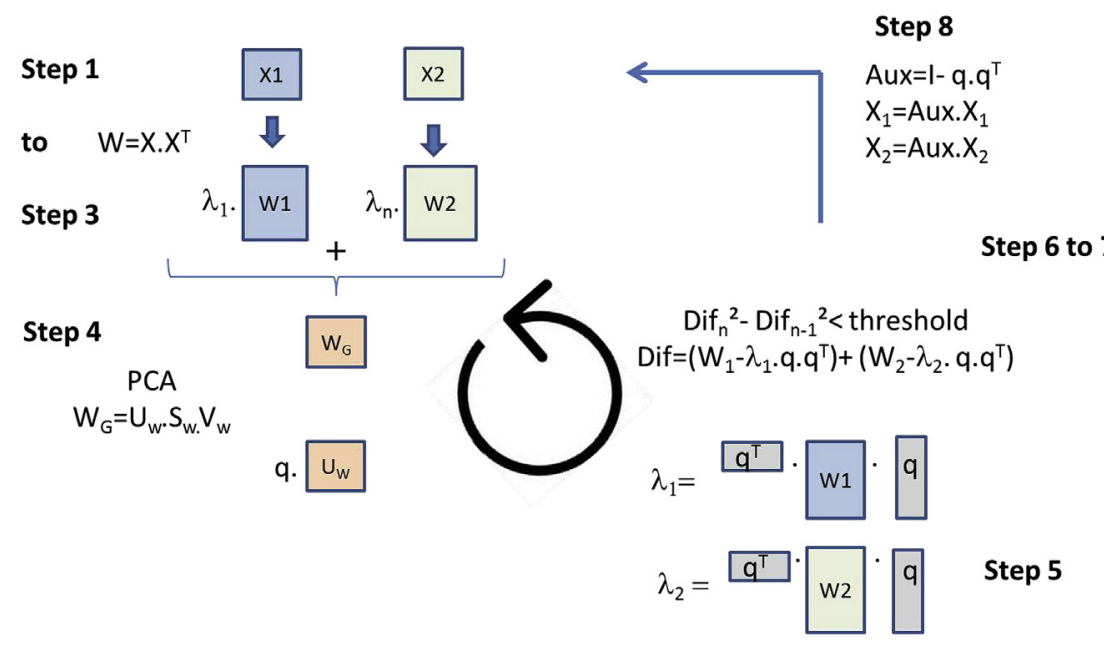

Fig. 1. Algorithm of the Common Components and Specific Weights Analysis or ComDim method [38].

Table 2

List of block index.

\begin{tabular}{ll}
\hline Block index & Factors and interactions \\
\hline 1 & Dose + Residuals matrix \\
2 & Ageing time + Residuals matrix \\
3 & Batch + Residuals matrix \\
4 & Dose x Ageing time + Residuals matrix \\
5 & Dose x Batch + Residuals matrix \\
6 & Ageing time x Batch + Residuals matrix \\
7 & Dose x Ageing time x Batch + Residuals matrix \\
8 & Residuals matrix \\
\hline
\end{tabular}

importance is given to the residual matrix by adding it back to factor and interaction matrices. Since all blocks contain then a contribution from the residual matrix, it is expected that the first Common Component will be due to the added residual error. Consequently and as CC1 is noise, the blocks that contribute significantly to CC1 (those with high saliences) contain mainly noise. The residual block should be the block with the largest salience on CC1. Blocks that contribute less contain sources of variability other than the noise.

As the saliences are proportional to variances [26], a comparison of variances is performed with an F-test. The block significance is then estimated with a Fisher test (student Fisher F-test) applied on the $F$-values $\left(F_{i}\right)$ calculated as per Equation (1). It would be as well possible to evaluate the significance with other evaluable test using high dimensional ANOVA approaches as ASCA, APCA and ANOVA TP $[40,41]$. For each data table, the ratio of the salience corresponding to the residual block on CC1 to the salience of this particular block on CC1 (Equation (1)) is calculated and these two saliences are compared using an F-test. The blocks whose salience is found to be statistically different from the residual block salience will be considered as being associated with significant factors (or interactions).

$\boldsymbol{F}_{i}=\frac{\lambda_{\text {res }}}{\lambda_{i}}$

where $\lambda_{\text {res }}$ is the salience of the residual block on CC1 and $\lambda_{i}$ is the salience of the $i$ th block on CC1.

The $F$-test is performed by selecting $n-1^{\circ}$ of freedom, where $n$ is the number of blocks. The significance level, so-called alpha level, is set equal to 0.01 to be considered statistically significant. The blocks for which $F_{i}$ is greater than the critical value $\left(F_{c}\right)$ of the Fisher table are considered as being related to influential factors or interactions. By examining the calculated saliences, it is possible to determine which $\mathrm{CC}$ is related to which factor or interaction. For the salience, the probability value ( $\mathrm{p}$-value) is also calculated for each F-test. It represents the probability that the variability is only due to noise. The more the p-value is close to zero and more the block is associated with a significant factor.

The relative importance of a factor compared to the residual noise is related to its salience value in the CC. In order to estimate the effect of the factor, it is possible to plot the sample scores on the informative $\mathrm{CC}_{\mathrm{i}}$ vs $\mathrm{CC} 1$. Loadings show how data values vary along a $\mathrm{CC}$ and are used to understand the meaning of the scores. The interpretation process is the same than a PCA. Loadings can have negative or positive values; so can scores. If the loading of a variable and the score of a sample on a particular CC have the same sign, they are related.

\section{Results and discussion}

\subsection{PE film}

The overlay of the spectra of PE layer in irradiated and nonirradiated PE film samples is illustrated in Fig. 2.

The IR peak assignments of the PE are done according to the literature [12,42-53]. As expected, the main changes in signal between irradiated and non-irradiated PE samples are observed in the carboxylic acid zone (around $1714 \mathrm{~cm}^{-1}$ ) and in the trans alkene zone (between 880 and $980 \mathrm{~cm}^{-1}$ ). Indeed, the peak at $1714 \mathrm{~cm}^{-1}$, identified as corresponding to carboxylic acid $[43,44,50]$, appears when the $\gamma$-dose increases, meaning that the $\gamma$-irradiation may cause polymer oxidation $[54,55]$. The peak at $964 \mathrm{~cm}^{-1}$, identified as corresponding to trans vinylene group $\left(-\mathrm{R}_{1}-\mathrm{CH}=\mathrm{CH}-\mathrm{R}_{2}\right)$ $[42,43,48,51]$, increases when the $\gamma$-dose increases. This implies that unsaturated compounds are generated after $\gamma$-irradiation. The peak at $730 \mathrm{~cm}^{-1}$ (shoulder) corresponding to the inner rocking vibration of $-\mathrm{CH}_{2}$ - in the crystalline part $[45,48]$ and the peak at $717 \mathrm{~cm}^{-1}$ corresponding to the inner rocking vibration of $-\mathrm{CH}_{2}-$ in the amorphous part $[45,48]$ seem not to be impacted by the $\gamma$ irradiation doses. Peaks at 2916 and $2848 \mathrm{~cm}^{-1}$ corresponding to the antisymmetric and symmetric stretching of $-\mathrm{CH}_{2}$ - groups and peaks included between 1470 and $1360 \mathrm{~cm}^{-1}$ corresponding to the deformation of $-\mathrm{CH}_{2}$ - and $-\mathrm{CH}_{3}$ - groups do not reveal any modifications of the polyethylene detectable by FTIR.

Given the large number of parameters generating a very large 


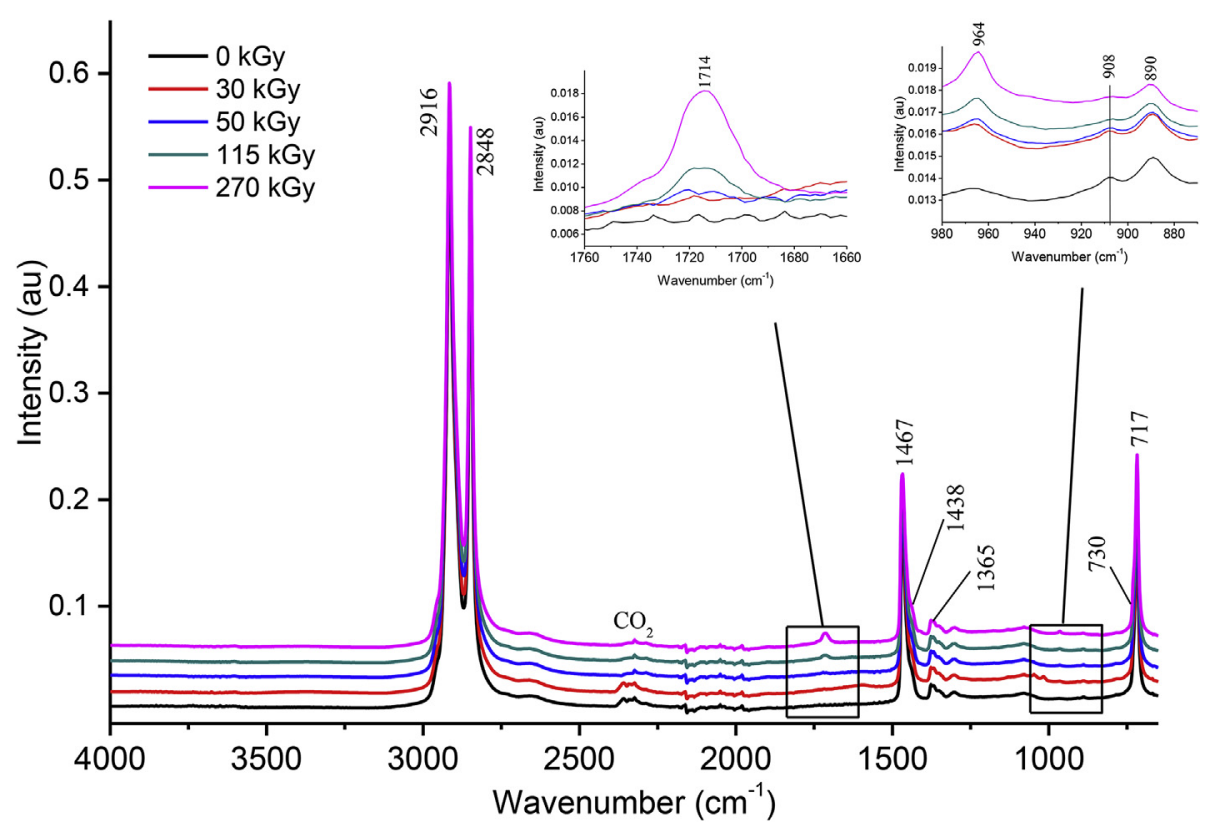

Fig. 2. ATR-FTIR spectra of PE film $\gamma$-irradiated at different doses. Only one lot spectra are represented here as spectra from other lots are equivalent.

amount of data, it is quantitatively difficult to define the influence of the factors. Thus, the chemometric method AComDim is used on the spectral area $1800-700 \mathrm{~cm}^{-1}$, which includes the modifications caused by the $\gamma$-irradiation discussed above. This method gives quantitative information about the variability associated to each factor.

Moreover, it is difficult to predict the batch-to-batch behaviour over time. The AComDim method is thus used to determine the impact of the different factors, and their interactions, such as the $\gamma$ doses, the natural ageing of the films and the film batches, which are considered as individual blocks. 476 spectra are recorded for all PE samples representing the effects of all $\gamma$-irradiation doses $(0,30$, $50,115,270 \mathrm{kGy}$ ), all ageing conditions (up to 6 months), and the four batches. The AComDim treatment is applied on FTIR spectra of PE films and the number of common dimensions is calculated based on the number of factors ( $\mathrm{n}$ ) by $2^{\mathrm{n}}$. In our case, eight common dimensions (or common components) are calculated.

The AComDim method gives the salience values of these blocks on each CC (common component, see Fig. 3). In AComDim, the CC1 (common component 1) describes the residual matrix. The less a block contributes to $\mathrm{CC} 1$, the more its source of variability is different from the residuals, i.e. the smaller its salience. The saliences make possible to find the significant factors.

According with Fig. 3a, three blocks (block 1, 2 and 4) are distinctly different from the block 8 (noise). In order to verify that the difference is significant, a Fisher test is applied. Each F-values (Fig. 3b) is computed from the salience on CC1, as the ratio between the salience of the residual block (i.e. the noise, block 8) and the salience of each other block (i.e., blocks 1-7). These F-values obtained after AComDim treatment are compared with the critical Fvalue $(\mathrm{Fc}=1.24)$ of the Fisher table according to the alpha level ( $\alpha=0.01$ by considering $475^{\circ}$ of freedom) (Fig. 3b). If $\alpha=0.05$ ( $\mathrm{FC}=1.16$ with $475^{\circ}$ of freedom for PE film in Fig. $3 \mathrm{~b}$ ), the significance of the interactions from factors 5 to 7 are border line: the factor 5 can be considered as significant at 95\% level and not at 99\% level while the factors 6 and 7 cannot be considered significant from $95 \%$ level.

Factors 1 (" $\gamma$-dose"), 2 ("natural ageing") and 4 (" $\gamma$ - dose $\times$ natural ageing" interaction) have F-values $(2.25,1.70$ and 1.72 , respectively) larger than the critical value of the Fisher table (Fc) and thus correspond to the significant factors. Factor 1 (" $\gamma$ dose") is the most significant, as expected, followed by factor 4 (" $\gamma$ dose $\times$ natural ageing" interaction) and factor 2 ("natural ageing"). The study of saliences (Fig. 3a, c-e) also makes it possible to assess the influential factors: the smaller the salience, the most influential the factor. The saliences confirm the results obtained with the Fvalues.

The score and loading plots for CC2 corresponding to the " $\gamma$ dose" factor are displayed in Fig. 4a) and b), respectively. The impact of the $\gamma$-dose on the film is not homogeneous; there are three distinct groups. In the first group, there is an overlap between the $30 \mathrm{kGy}$ irradiated group, the $50 \mathrm{kGy}$ irradiated group and the non-irradiated group showing that the impact of the $\gamma$-irradiation dose is minimized as these doses. Even though the impact of the $\gamma$ dose is minimized there is however a certain clustering for each dose showing polymer modification after first doses. The $\gamma$-irradiation impact becomes significant from $115 \mathrm{kGy}$ as second group constitutes a homogeneous group as does the $270 \mathrm{kGy}$ third group which are projected in the positive part of the score plot (Fig. 4a). Indeed, the positive part of the loading is correlated with the high $\gamma$-doses of the score plot displayed in Fig. 4b. There is a correlation between the evolution of the " $\gamma$-dose" factor and that of the areas of the carbonyl peak $\left(1714 \mathrm{~cm}^{-1}\right)$, of the $-\mathrm{CH}_{2}$ deformation peak $\left(1473 \mathrm{~cm}^{-1}\right)$ and of the peak at $964 \mathrm{~cm}^{-1}(\nu \mathrm{C}=\mathrm{C}$ trans). The areas of the carboxylic acid peak and unsaturated function peak increase with the $\gamma$-dose and the deformation of the $-\mathrm{CH}_{2}$ peak changes because its environment changes. This means that under $\gamma$-irradiation, modifications, and especially oxidation, of PE occur at the surface of the film.

The score and loading plots for CC6 corresponding to the "natural ageing" factor are displayed in Fig. $4 \mathrm{c}$ and d, respectively. The groups are projected according to natural ageing times (Fig. 4c). There is a temporal gap between $\mathrm{T} 2 \mathrm{~m}$ (2months) and $\mathrm{T} 3 \mathrm{~m}$ (3months). This temporal gap has been reported in a previous study on radicals [14]. There is a correlation between the evolution of the "natural ageing" factor and that of the areas of the $-\mathrm{CH}_{2}$ - 


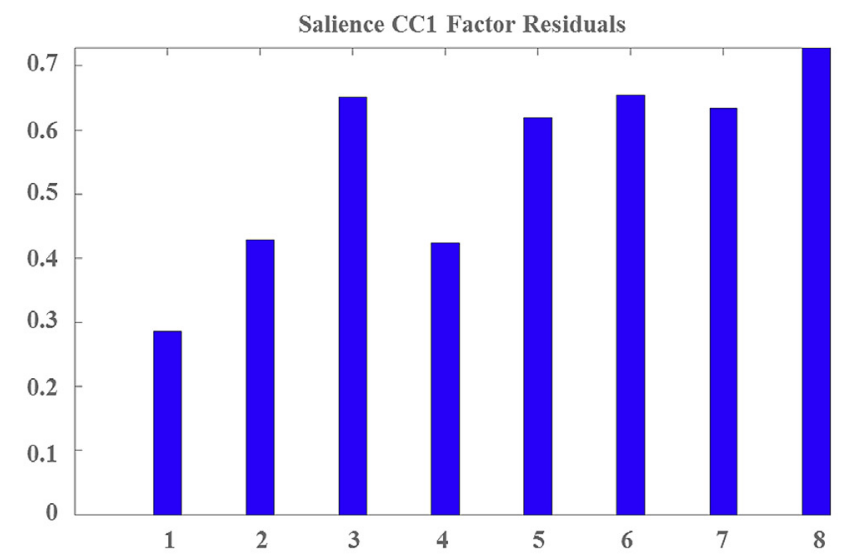

a)

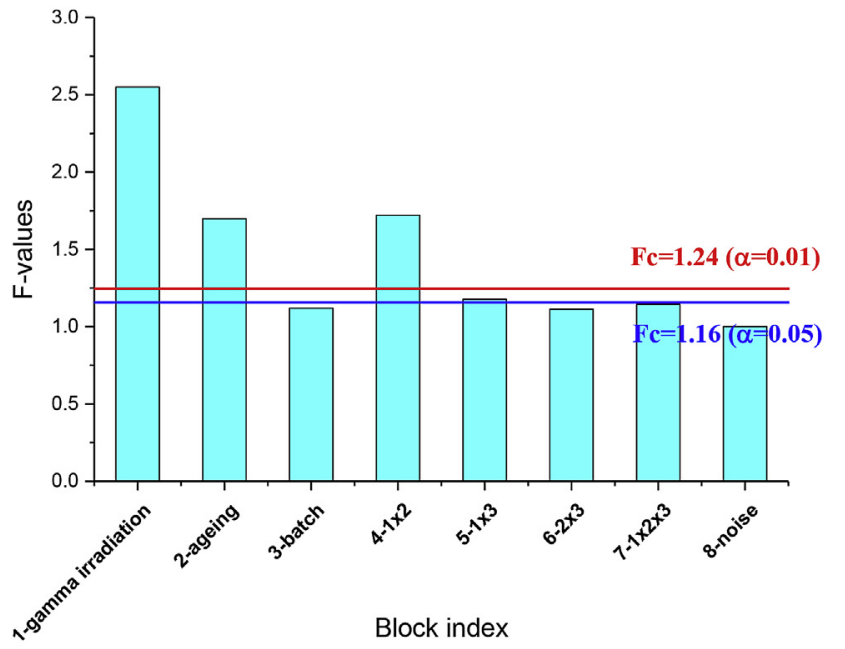

b)

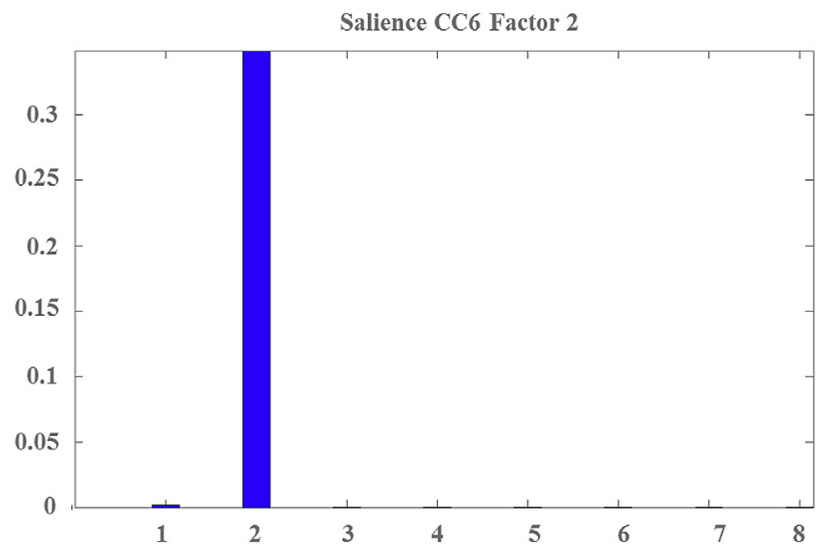

d)

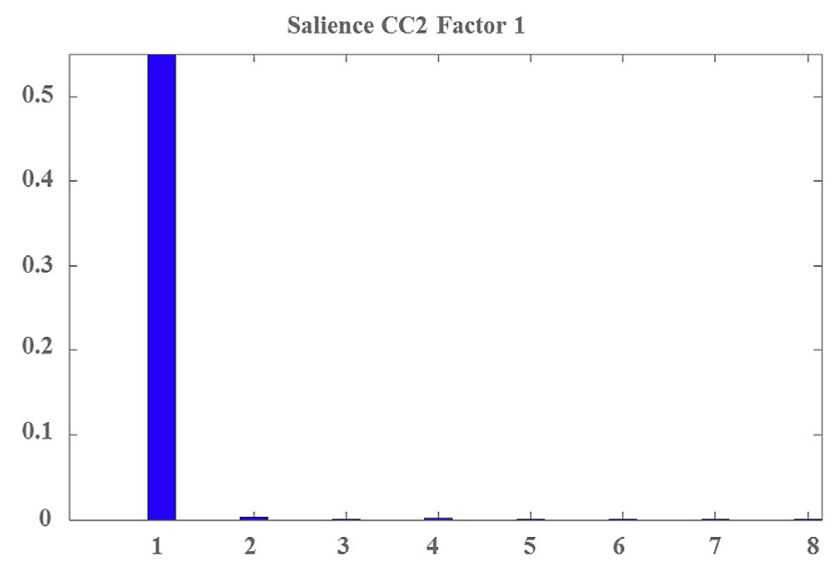

c)

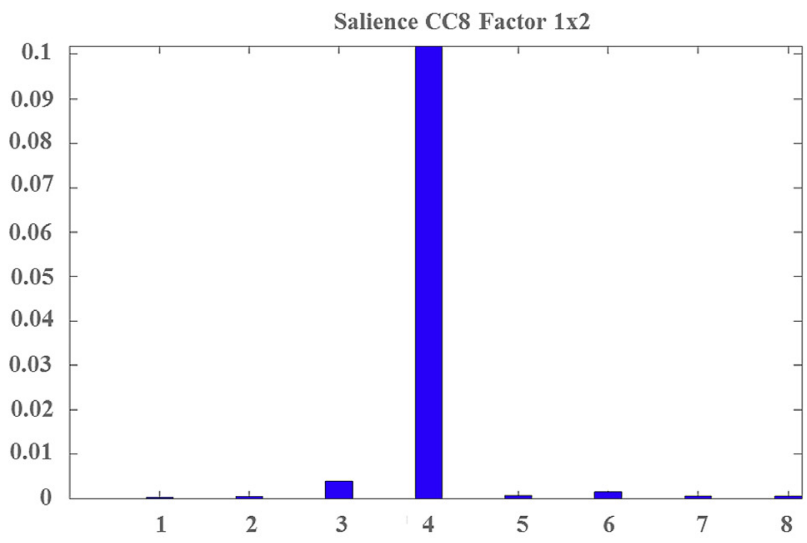

e)

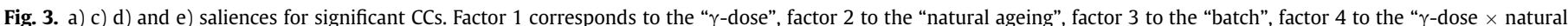

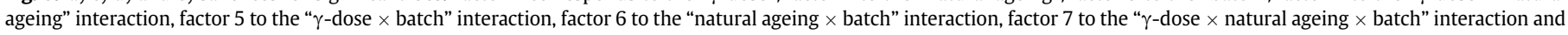
factor 8 to the noise. b) F-values compared with critical F-value for the internal side of PE film MIR-ATR data.

deformation peak and of the peaks at $715-730 \mathrm{~cm}^{-1}$ characteristic of a long aliphatic chain group. According to the literature $[20,56,57]$, the $1471: 730$ peak ratio represents the crystallinity.
Over time, there is a shift and a modification of the crystallinity. Moreover, this factor is correlated with peaks at 1047 and $1018 \mathrm{~cm}^{-1}$, which are probably the fingerprints of short 


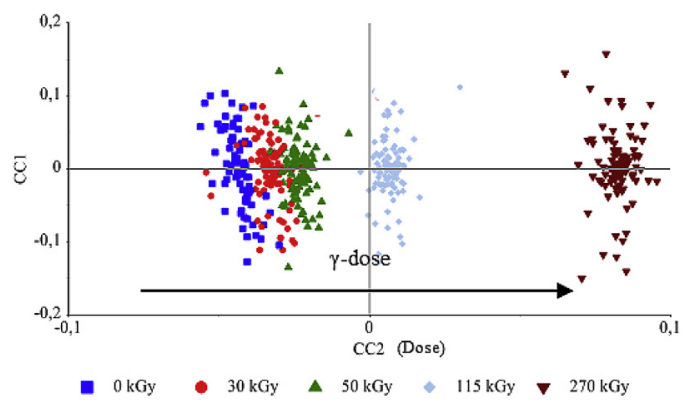

a)

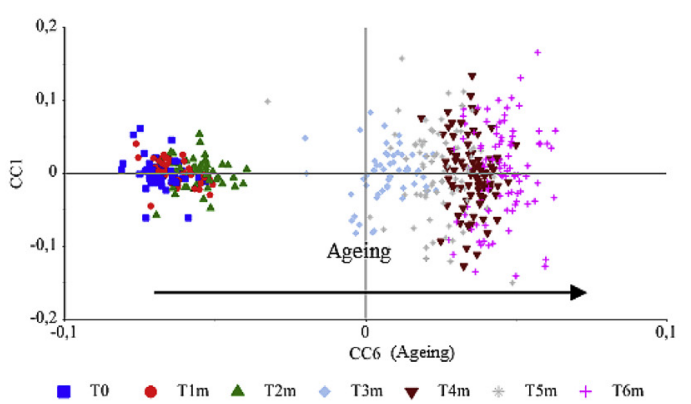

c)

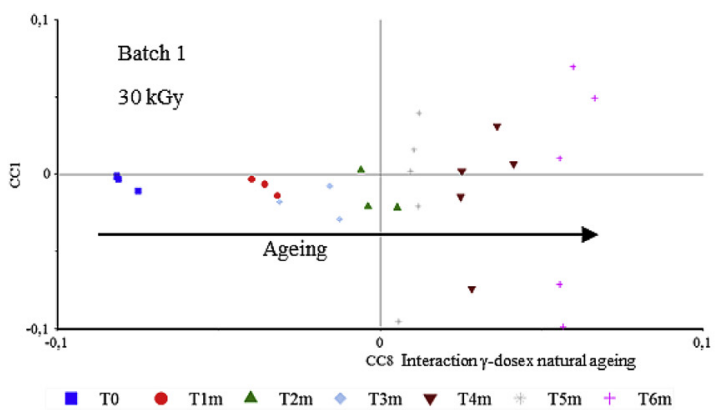

e)

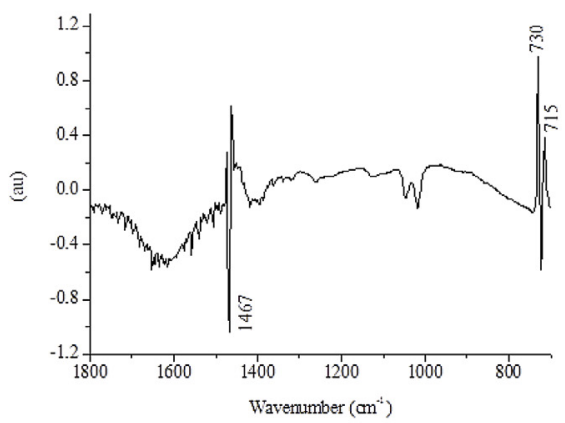

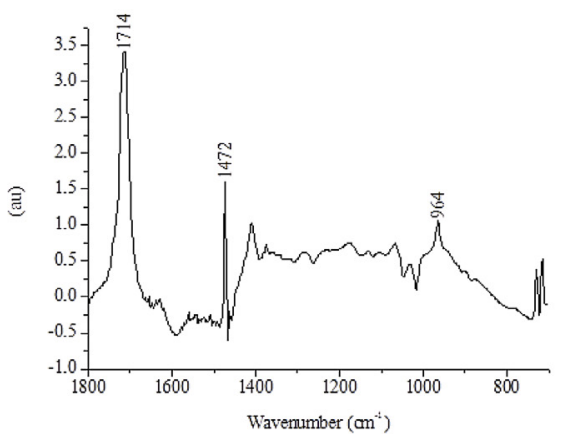

b)

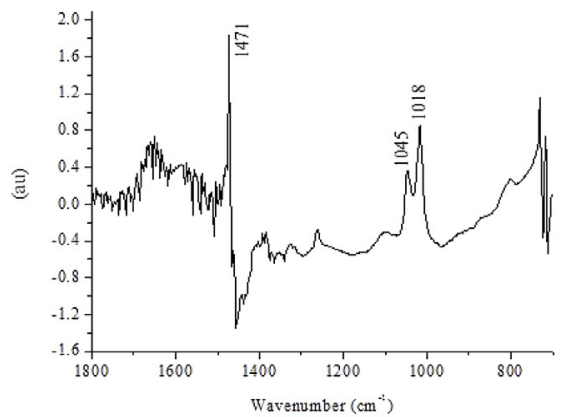

d)

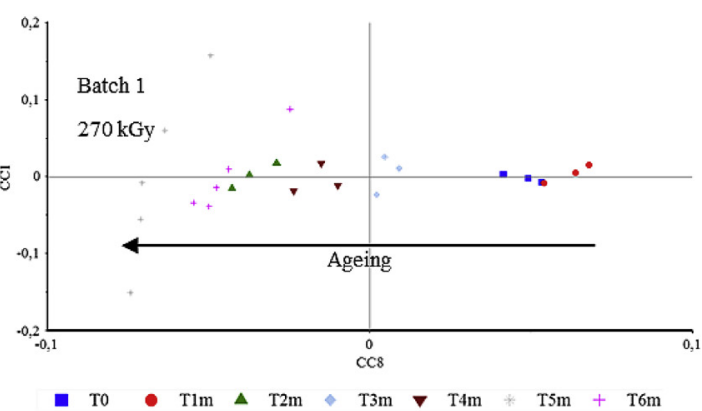

f)

g)

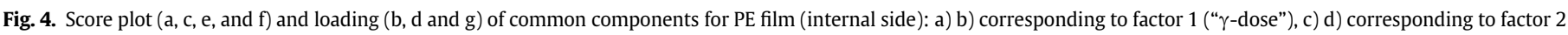

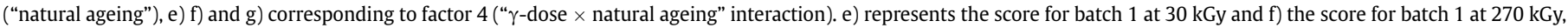
these two examples have been chosen here to illustrate the observations, as the same observations are made for the four batches. 
unbranched unsaturated chain in the trans configuration [58]. These observations suggest that cross-linking and scission events occur over time. The peak assigned to carboxylic acid is not impacted by natural ageing, which means that after carboxylic acid is formed during $\gamma$-irradiation, it remains stable and is not damaged. The same comments hold for the peak at $964 \mathrm{~cm}^{-1}$.

Fig. $4 \mathrm{e}, \mathrm{f}$ and $\mathrm{g}$ represent the score plots and the loading plot for CC8 corresponding to the " $\gamma$-dose $\times$ natural ageing" interaction for PE film batch 1 at $30 \mathrm{kGy}$ (Fig. 4e) and $270 \mathrm{kGy}$ (Fig. 4f). Only results on one lot is presented for the sake of clarity as there is a large dispersion of the data that could be accounted by the large number of the analyzed spectra, corresponding to the interaction between the different $\gamma$-doses, the different ageing and the different batches. In Fig. $4 \mathrm{e}$, the samples are grouped according the ageing time and the groups are oriented from left to right due to a change of $-\mathrm{CH}_{2}$ environment (Fig. 4g). In Fig. 4f, the displacement over time is the reverse of that in Fig. $4 \mathrm{e}$ and the positioning of the $\mathrm{T} 1 \mathrm{~m}$ and $\mathrm{T} 2 \mathrm{~m}$ groups are incorrect [59], leading to difficulties of this interaction interpretation. It would mean that the $30 \mathrm{kGy}$ irradiation dose provokes an increase of the crystallinity while at $270 \mathrm{kGy}$ irradiation dose the crystallites seem to be damaged [20-57]. Indeed the ageing and the $\gamma$-dose are correlated and are impacted differently depending on the dose or the ageing. Different $\gamma$-doses are associated with a slightly different natural ageing which correspond to a variation of the crystallinity as a function of the $\gamma$-dose (Fig. $4 \mathrm{~g}$ )). Other transformations observed just after $\gamma$-irradiation such as carboxylic acid generation and unsaturated chains formation are not impacted presently.

\subsection{EVA film}

The overlay of spectra of the EVA film of irradiated and nonirradiated EVA samples is illustrated in Fig. 5.

The IR assignments of the EVA, which allow the identification of changes are done according to the literature $[20,43-46,48-50,52,53,58]$. Peaks at 2916 and $2848 \mathrm{~cm}^{-1}$ correspond to the antisymmetric and symmetric stretching of $-\mathrm{CH}_{2}-$ groups. Peaks included between 1470 and $1360 \mathrm{~cm}^{-1}$ correspond to the deformation of $-\mathrm{CH}_{2}$ - and $-\mathrm{CH}_{3}$ - groups. Peaks at $720-730 \mathrm{~cm}^{-1}$ are characteristic of long chains of $-\mathrm{CH}_{2}$ - present in PE. Peaks at 1739,1238 and $1020 \mathrm{~cm}^{-1}$ characterize the vinyl acetate moiety. The peak at $964 \mathrm{~cm}^{-1}$, identified as corresponding to trans vinylene group $\left(-\mathrm{R}_{1}-\mathrm{CH}=\mathrm{CH}-\mathrm{R}_{2}\right)[42,43,48,51]$. The peak at $1714 \mathrm{~cm}^{-1}$ corresponds to $v-C=O$ stretching in carboxylic acid $[43,44,50]$.

In the same way as before, the AComDim method is used to quantify the impact of each factor and their interactions, as the $\gamma$ doses, the natural ageing of films and the film batches. In the same way as for the PE film, eight common dimensions (or common components) are calculated from a data matrix of 293 samples representing the effects of all $\gamma$-irradiation doses $(0,30,50,115$, $270 \mathrm{kGy})$, all ageing conditions ( $0,1,2,3,4,5$ and 6 months), and the three batches. The correspondence between blocks (blocks 1 to 8 ) and factors is the same as for the PE film.

Factor 1 (" $\gamma$-dose") is the most significant, followed by the factor 2 ("natural ageing") and by the factor 4 (" $\gamma$-dose $\times$ natural ageing" interaction). The study of saliences (Fig. 6a, c-e) makes possible to assess the influential factors from these calculations.

According with Fig. 6a, three blocks (block1, 2 and 4) are distinctly different from the block 8 (noise). In order to verify that the difference is significant, a Fisher test is applied. Fig. $6 \mathrm{~b}$ shows the F-values for the internal side of the EVA film. Factors 1 ( " $\gamma$ dose"), 2 ("natural ageing") and 4 (" $\gamma$-dose $\times$ natural ageing" interaction) have F-values (4.87, 3.63, and 2.83, respectively) larger than the critical value of the Fisher table $(\mathrm{Fc})$ and thus are the significant factors. The critical F-value $(\mathrm{Fc}=1.31)$ of the Fisher table is obtained according to the alpha level $(\alpha=0.01$ by considering $292^{\circ}$ of freedom). If $\alpha=0.05$ (Fc $=1.21$ with $292^{\circ}$ of freedom for EVA film in Fig. 6b), the significance of the interactions from factors 5 to 7 are border line: the factor 7 can be considered as significant at 95\% level and not at 99\% level while the factors 5 and 6 cannot be considered significant from 95\% level.

The score plot and loading for CC3 corresponding to the " $\gamma$ dose" factor are displayed in Fig. 7a and b, respectively. The $\gamma$ irradiation induces modifications proportionally to the dose. The

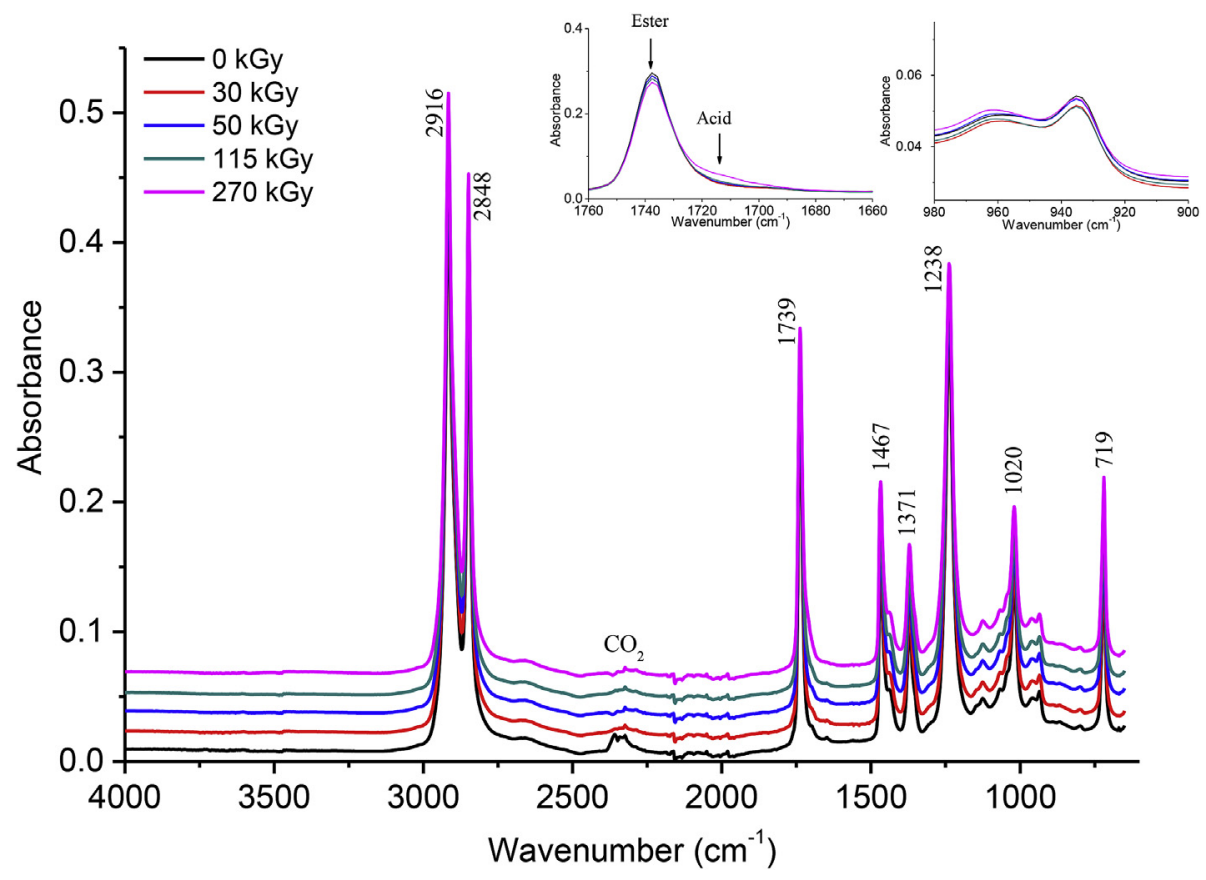

Fig. 5. ATR-FTIR spectra of EVA film $\gamma$-irradiated at different doses. Only one lot spectra are represented here as spectra from other lots are equivalent. 


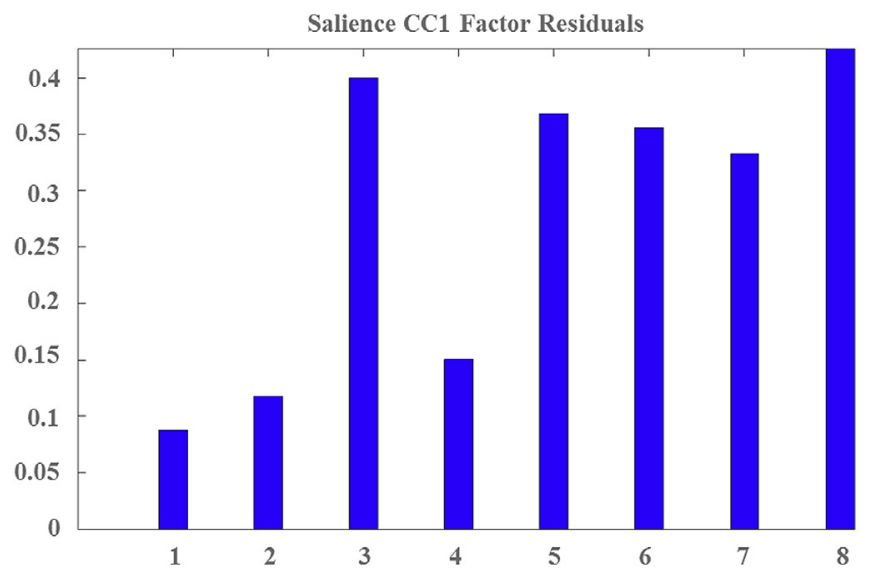

a)
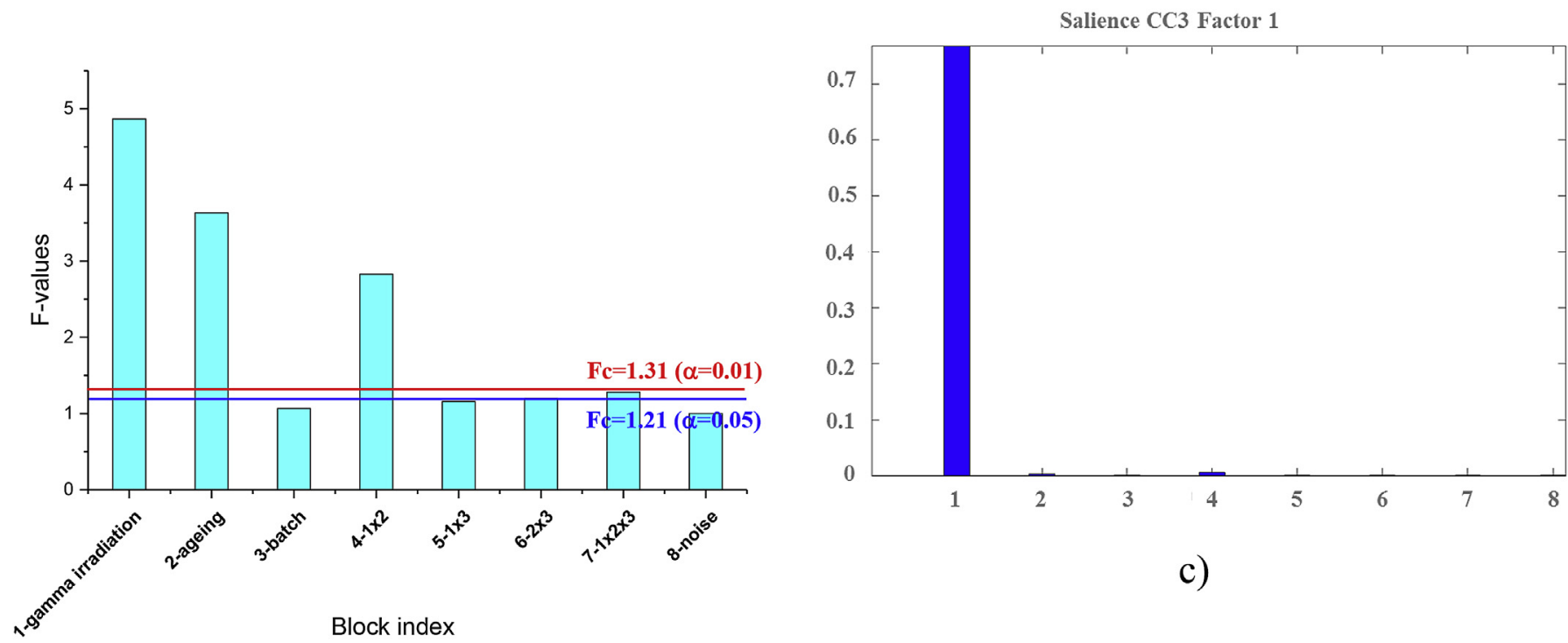

c)

b)

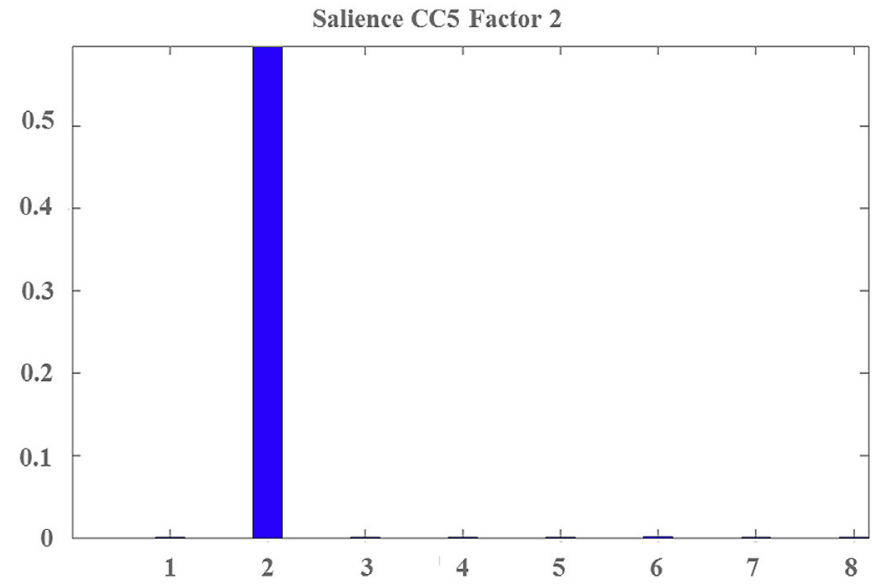

d)

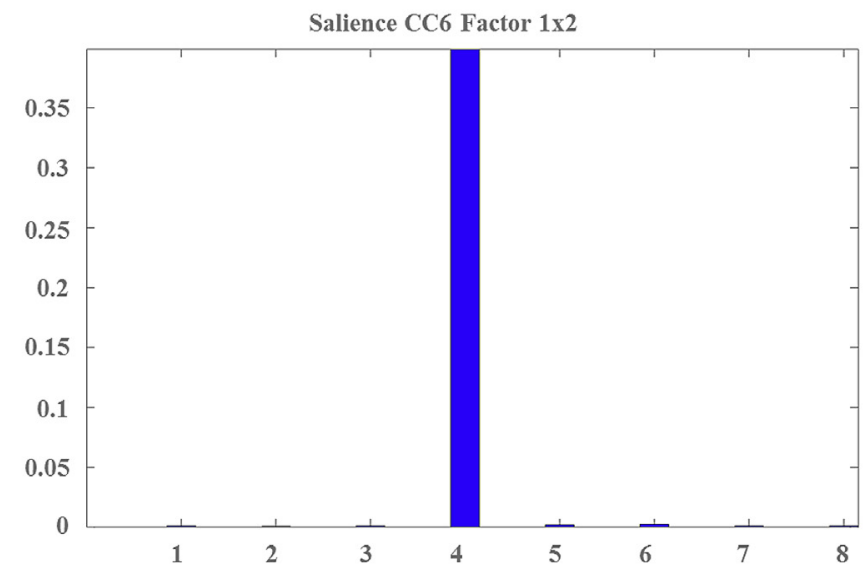

e)

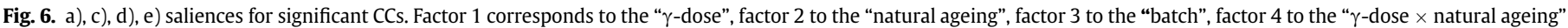

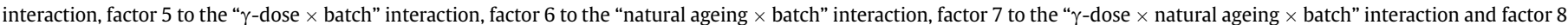
to the noise. b) F-values compared with critical F-value for the internal side of EVA film MIR-ATR data. 


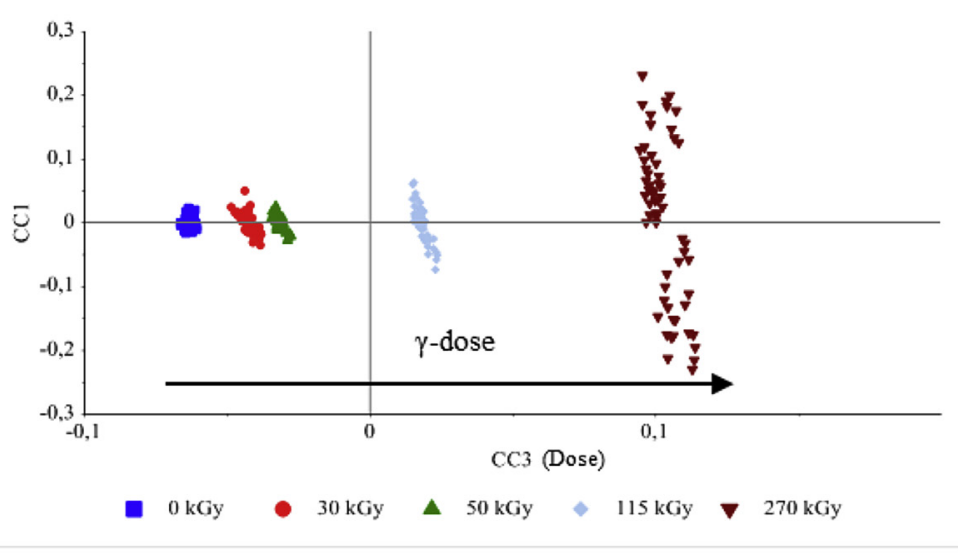

a)

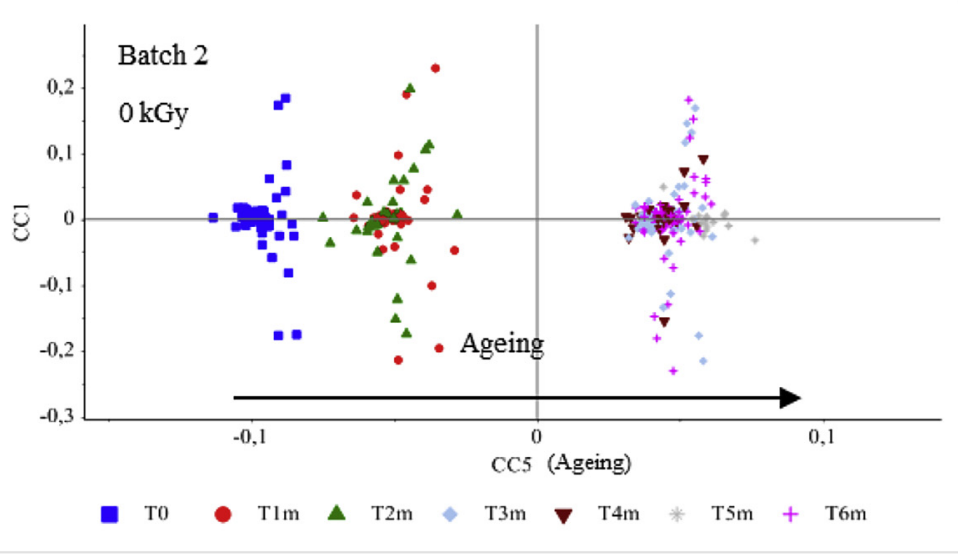

c)

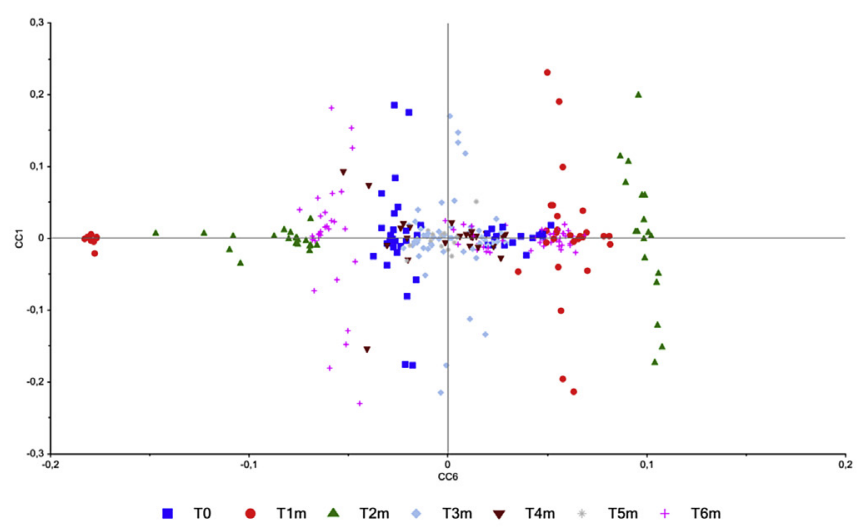

e)

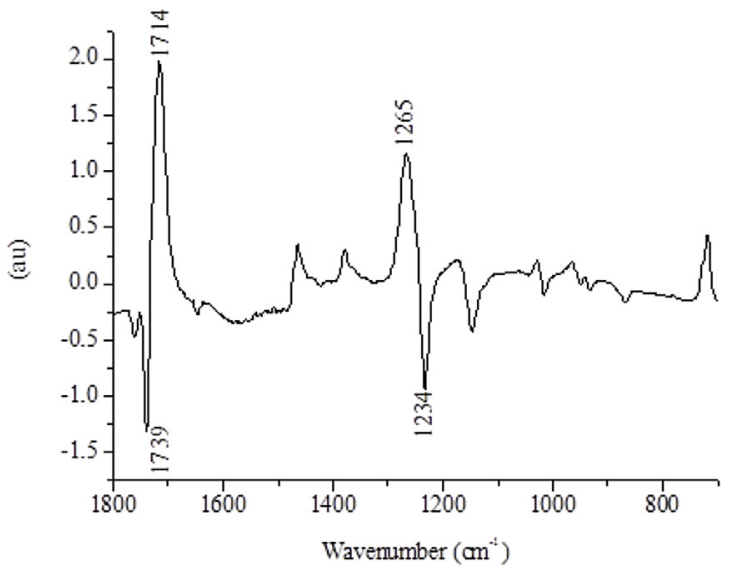

b)

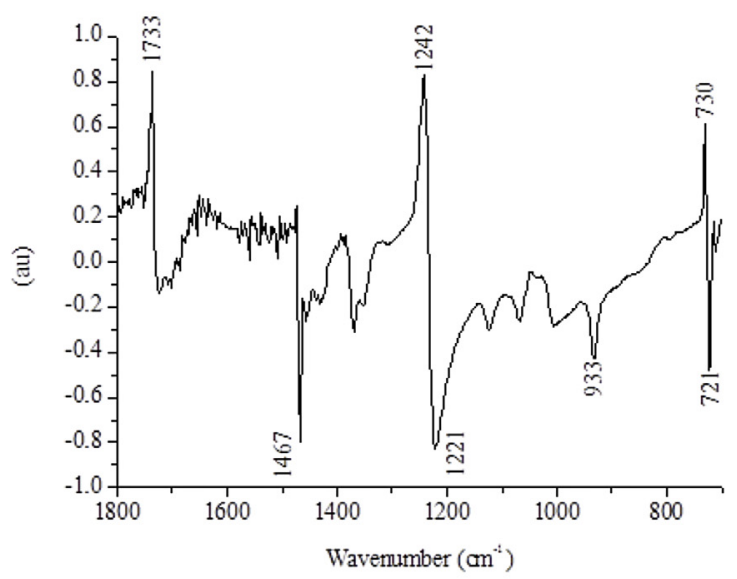

d)

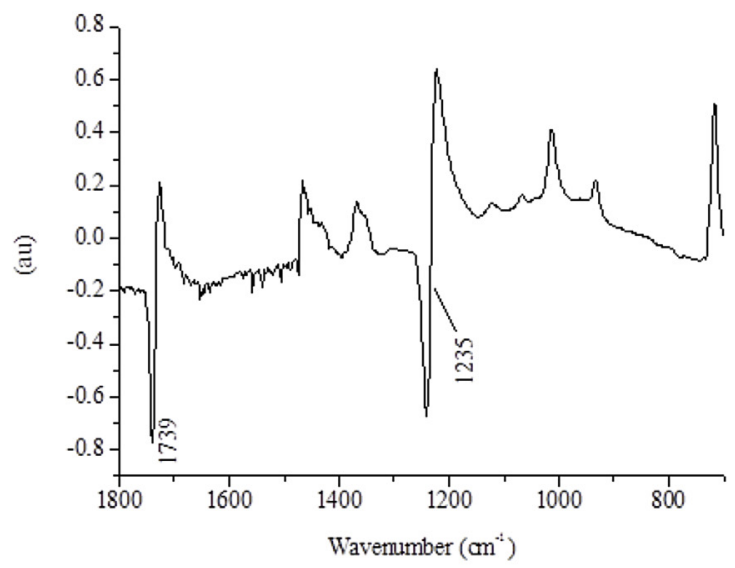

f)

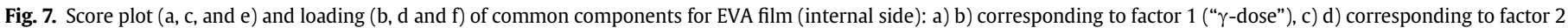

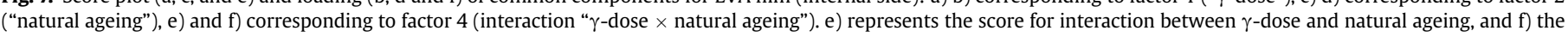
loading. 
different groups for the different $\gamma$-doses are quantitatively spaced out on the scores plot (Fig. 7a): samples in the $30 \mathrm{kGy}$ group, the $50 \mathrm{kGy}$ group and the non-irradiated group are closer to one another than samples in the $115 \mathrm{kGy}$ and $270 \mathrm{kGy}$ groups. Samples in the $270 \mathrm{kGy}$ group are the most scattered due to the inhomogeneity of the surface. The groups are better separated in the case of the EVA film than the PE film (Fig. 4 a). Indeed, in the case of the EVA film there is no noise on spectra around the carbonyl peak of an ester function. However, in the case of the PE film, the peak assigned to the acid raises above the noise, explaining the overlap between the 0,30 and $50 \mathrm{kGy}$ groups, indicating that the $\gamma$-irradiation effect is higher in the EVA film than that in the PE film. In Fig. $7 \mathrm{~b}$, the positive part of the loading increases with the $\gamma$-dose, and inversely, the negative part of the loading decreases with the $\gamma$ dose. The evolution of the " $\gamma$-dose" factor is essentially correlated with the carboxylic acid fingerprints $\left(1714 \mathrm{~cm}^{-1}, v-C=0\right.$, and $\left.1265 \mathrm{~cm}^{-1}, v-\mathrm{C}-\mathrm{O}\right)$ and with the ester fingerprints $\left(1739 \mathrm{~cm}^{-1}, v-\right.$ $\mathrm{C}=\mathrm{O}$, and $\left.1234 \mathrm{~cm}^{-1}, v-\mathrm{C}-\mathrm{O}\right)$.

Indeed, the areas of the peaks corresponding to carboxylic acid increase when the $\gamma$-dose increases and the areas of the peaks corresponding to the acetate group decrease when the $\gamma$-dose increases. These observations mean that $\gamma$-irradiation induces chemical reactions on the acetate moiety, generating a carboxylic acid function: the acetate moiety is transformed into carboxylate moiety.

The score plot and loading for CC5 corresponding to the "natural ageing" factor are displayed in Fig. 7c and d, respectively. In Fig. 7c, the groups are thus projected according to the natural ageing time. The fact that the loading curve looks like to be a derivative (Fig. 7d) shows there are changes in the environment of the ester and changes on long aliphatic chain groups over time. The ester $v \mathrm{C}=\mathrm{O}$ peak shifts to $1735 \mathrm{~cm}^{-1}$ and the ester $v \mathrm{C}-\mathrm{O}$ peak shifts to $1242 \mathrm{~cm}^{-1}$. The hydrolysis of the ester into carboxylic acid by air is entirely conceivable. There is also a correlation between the evolution of natural ageing and that of the areas of the $-\mathrm{CH}_{2}$ - deformation peaks $\left(1467 \mathrm{~cm}^{-1}\right)$ and of the peaks characteristic of long aliphatic chain groups $\left(715-730 \mathrm{~cm}^{-1}\right)$. The variations of these peaks imply that scission and cross-linking processes occur over time as well.

Fig. 7e represents the score plots of the " $\gamma$-dose $\times$ natural ageing" interaction for the internal side of the EVA film. This interaction presently means there is an evolution over time differently according to the $\gamma$-dose. Fig. 7c shows that non-sterile samples undergo a continuous ageing. On contrary, $\gamma$-irradiated samples undergo a non-linear ageing as ageing effect seems reaching a maximum at $\mathrm{T} 2 \mathrm{~m}$ ( 2 months). Indeed, the ageing of irradiated samples until T2m is projected in a direction, and after $\mathrm{T} 3 \mathrm{~m}$ the ageing is projected in the opposite direction. The score plot labelled according to ageing time and for all $\gamma$-doses shows equivalent observations. The score plot labelled $\gamma$-doses is available in Fig. 7e. There is either modification of the environment of the ester or formation of other carbonyl compounds. Whatever the hypothesis, the species created might be volatile, since at $\mathrm{T} 6 \mathrm{~m}$ the polymer reverts back to its initial state (T0) regarding chemical feature on the surface. It should mean that aged $\gamma$-irradiated EVA film presents chemical moieties comparable to non-sterile EVA film.

\subsection{Extrapolation of films behaviour during ageing}

AComDim method applied on FTIR spectra recorded on PE film and EVA film highlights the impact of ageing after $\gamma$-irradiation and shows that ageing evolves differently in the PE and EVA polymers. The modifications induced in PE film evolve linearly over time up to 6 months without reaching a visible plateau. On the contrary, the modifications induced in EVA film progress non-linearly with time, which could be due to the formation of volatile species. The trends of change are shown schematically in Fig. 8.

\section{Conclusion}

It is clear that $\gamma$-irradiation affords modifications of polymeric material. Formation of carboxylic acids, of a trans unsaturated groups and modifications of the environment (in terms of $-\mathrm{CH}_{2}$ groups) are the major changes induced by $\gamma$-irradiation in polymer materials.

In our study, the AComDim method was used to rank the influential factors, such as the $\gamma$-doses, the natural ageing and to subsequently emphasized their interaction between all influencing factors, which come into play in PE and EVA based multilayer films after $\gamma$-irradiation at different doses $(0,30,50,115$ and $270 \mathrm{kGy})$ and over natural ageing (up to 6 months).

Observations suggest that cross-linking and scission events occur over time for the PE film. Carboxylic acids seem not to be impacted by natural ageing, which means that after carboxylic acid is formed during $\gamma$-irradiation, it remains stable and is not damaged.

The behaviour of PE film and EVA film during ageing after $\gamma$ irradiation is different. The PE film presents a linear variation and EVA film present a non-linearly evolution with time. All results showed as well that there is no batch effect; only the material nature is or is not sensitive to changes induced by $\gamma$-irradiation.

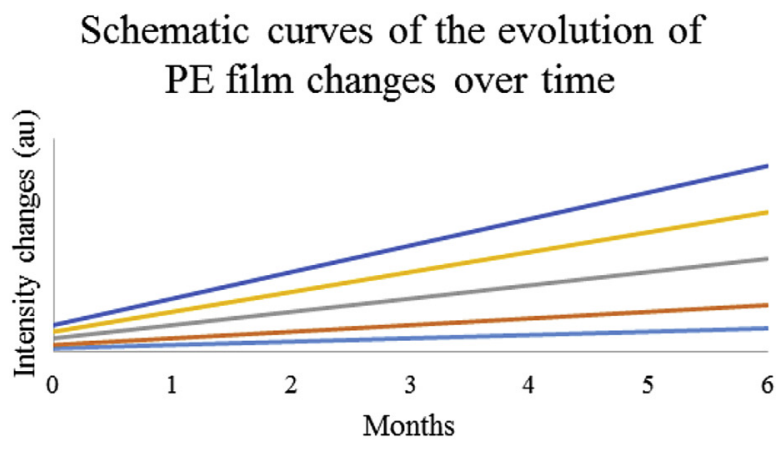

a)

\section{Schematic curves of the evolution of EVA film changes over time}

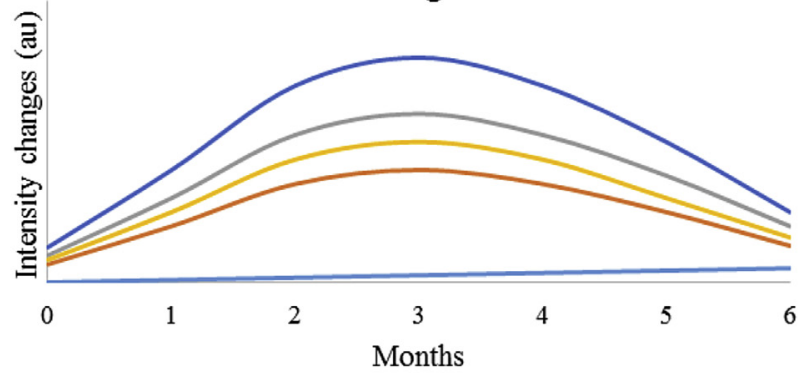

b)

Fig. 8. Schematic representation of the changes over time for the PE (a)) and EVA (b)) materials. 0 kGy corresponds to the lowest curve and 270 kGy to the highest curve. 
Based on AComDim approach on FTIR-ATR spectra, it shows that the extent of damage to the polymers due to irradiation (at the $\sim 30-50 \mathrm{kGy}$ dose) does not alter significantly the material integrity for its intended purpose. An ESR study [14] and additional results on water permeability show likewise a good stability of the global features of films.

\section{Acknowledgements}

FG thanks Sartorius Stedim Biotech for PhD grant. ND and SRAM are thankful to AMU and CNRS for support, and to Sartorius Stedim Biotech for funding.

\section{References}

[1] S.S. Zyryanov, A.V. Kruzhalov, F.G. Neshov, O.V. Ryaboukhin, On the oxidation of polyethylene under irradiation, J. Surf. Investigation 9 (2015) 368-370.

[2] M. Hamzah, A. Rjeb, D. Sqalli Houssaini, S. Sayouri, M. Darhouri, Comparative study of unstabilized and stabilized polyethylene aged under natural weathering by using ATR-FTIR spectroscopy, Phys. Chem. News 70 (2013) 7.

[3] M.D. Failla, A. Brandolin, C. Sarmoria, E.M. Vallés, The effect of oxygen on the irradiation process of ethylene-butene copolymer, Polym. Degrad. Stab. 97 (2012) 1485-1494.

[4] M. Sudol, K. Czaja, Effect of electron beam irradiation and plastic deformation on molar mass of medical grade ultra-high molecular weight polyethylene, Polimery 55 (2010) 890-894.

[5] N. Billamboz, M. Grivet, S. Foley, G. Baldacchino, J.-C. Hubinois, Radiolysis of the polyethylene/water system: studies on the role of hydroxyl radical, Radiat. Phys. Chem. 79 (2010) 36-40.

[6] M. Ferry, E. Pellizzi, I. Boughattas, E. Fromentin, V. Dauvois, G. de Combarieu, P. Coignet, F. Cochin, Y. Ngono-Ravache, E. Balanzat, S. Esnouf, Effect of cumulated dose on hydrogen emission from polyethylene irradiated under oxidative atmosphere using gamma rays and ion beams, Radiat. Phys. Chem. 118 (2016) 124-127.

[7] J. Verdu, Oxidative Ageing of Polymers, John Wiley \& Sons, Inc, 2012, pp. 277-319.

[8] M. Zenkiewicz, M. Rauchfleisz, J. Czuprynska, Comparison of some oxidation effects in polyethylene film irradiated with electron beam or gamma rays, Radiat. Phys. Chem. 68 (2003) 799-809.

[9] I. Carpentieri, V. Brunella, P. Bracco, M.C. Paganini, E.M. Brach del Prever, M.P. Luda, S. Bonomi, L. Costa, Post-irradiation oxidation of different polyethylenes, Polym. Degrad. Stab. 96 (2011) 624-629.

[10] N. Khelidj, X. Colin, L. Audouin, J. Verdu, C. Monchy-Leroy, V. Prunier, Oxidation of polyethylene under irradiation at low temperature and low dose rate. Part I. The case of "pure" radiochemical initiation, Polym. Degrad. Stab. 91 (2006) 1593-1597.

[11] Guide to Irradiation and Sterilization Validation of Single-use Bioprocess Systems, Bioprocess International, may 2008, p. 12.

[12] A. Traboulsi, N. Dupuy, C. Rebufa, M. Sergent, Investigation of gamma radiation effect on the anion exchange resin Amberlite IRA-400 in hydroxide form by Fourier transformed infrared and ${ }^{13} \mathrm{C}$ nuclear magnetic resonance spectroscopies, Anal. Chim. Acta 717 (2012) 110-121.

[13] A.E. Goulas, K.A. Riganakos, M.G. Kontominas, Effect of ionizing radiation on physicochemical and mechanical properties of commercial multilayer coextruded flexible plastics packaging materials, Radiat. Phys. Chem. 68 (2003) 865-872.

[14] G. Audran, S. Dorey, N. Dupuy, F. Gaston, S.R.A. Marque, Degradation of girradiated polyethylene-ethylene vinyl alcoholpolyethylene multilayer films: an ESR study, Polym. Degrad. Stab. 122 (2015) 169-179.

[15] M. Driffield, E. Bradley, L. Castle, Literature Review, Analytical Screening and Chemical Migration Studies on Irradiated Food Packaging, 2009.

[16] J.C.M. Suarez, E.B. Mano, Characterization of degradation on gammairradiated recycled polyethylene blends by scanning electron microscopy, Polym. Degrad. Stab. 72 (2001) 217-221.

[17] K.J. Hemmerich, Medical Device and Diagnostic Industry, 2000 online, http:// www.mddionline.com/article/polymer-materials-selection-radiationsterilized-products.

[18] N.H. Stoffers, J.P.H. Linssen, R. Franz, F. Welle, Migration and sensory evaluation of irradiated polymers, Radiat. Phys. Chem. 71 (2004) 203-206.

[19] P.G. Demertzis, R. Franz, F. Welle, The effects of $\gamma$-irradiation on compositional changes in plastic packaging films, Packag. Technol. Sci. 12 (1999) 119-130.

[20] D. Klepac, M. Scetar, G. Baranovic, K. Galic, S. Valic, Influence of high doses $\gamma$ irradiation on oxygen permeability of linear low-density polyethylene and cast polypropylene films, Radiat. Phys. Chem. 97 (2014) 304-312.

[21] M. Kaci, H. Djidjelli, T. Boukedami, Study of the effect of gamma irradiation on the structure and properties of metallocene linear low density polyethylene containing hindered amines, Polym. Bull. 60 (2008) 387-395.

[22] A. Buttafava, A. Tavares, M. Arimondi, A. Zaopo, S. Nesti, D. Dondi, M. Mariani, A. Faucitano, Dose rate effects on the radiation induced oxidation of polyethylene, Nucl. Instrum. Methods Phys. Res. Sect. B 265 (2007) 221-226.
[23] F. Khodkar, N.G. Ebrahimi, Effect of irradiation on mechanical and structural properties of ethylene vinyl acetate copolymers hollow fibers, J. Appl. Polym. Sci. 119 (2011) 2085-2092.

[24] F. Gaston, N. Dupuy, S.R.A. Marque, M. Barbaroux, S. Dorey, One year monitoring by FTIR of $\gamma$-irradiated multilayer film PE/EVOH/PE, Radiat. Phys. Chem. 125 (2016) 115-121.

[25] F. Gaston, N. Dupuy, S.R.A. Marque, M. Barbaroux, S. Dorey, FTIR study of ageing of $\gamma$-irradiated biopharmaceutical EVA based film, Polym. Degrad. Stab. 129 (2016) 19-25.

[26] D. Jouan-Rimbaud Bouveresse, R. Climaco Pinto, L.M. Schmidtke, N. Locquet, D.N. Rutledge, Identification of significant factors by an extension of ANOVA-PCA based on multi-block analysis, Chemom. Intelligent Lab. Syst. 106 (2011) 173-182.

[27] S. Amat, N. Dupuy, J. Kister, D.N. Rutledge, Development of near infrared sensors: detection of influential factors by the AComDim method, Anal. Chim. Acta 675 (2010) 16-23.

[28] D. Plaehn, D.S. Lundahl, An L-PLS preference cluster analysis on French consumer hedonics to fresh tomatoes, Food Qual. Prefer. 17 (2006) 243-256.

[29] D.C. Plaehn, D.S. Lundahl, Regression with multiple regressor arrays, J. Chemom. 21 (2007) 621-634.

[30] K. Muteki, J.F. MacGregor, Multi-block PLS modeling for L-shape data structures with applications to mixture modeling, Chemom. Intelligent Lab. Syst. 85 (2007) 186-194.

[31] E.M. Qannari, I. Wakeling, P. Courcoux, H.J.H. MacFie, Defining the underlying sensory dimensions, Food Qual. Prefer. 11 (2000) 151-154.

[32] M. Hanafi, E.M. Qannari, Nouvelles propriétés de l'analyse en composantes communes et poids spécifiques, J. Soc. Fr. Stat. 149 (2008) 75-97.

[33] E.M. Qannari, P. Courcoux, E. Vigneau, Common components and specific weights analysis performed on preference data, Food Qual. Prefer. 12 (2001) 365-368.

[34] M. Hanafi, G. Mazerolles, E. Dufour, E.M. Qannari, Common components and specific weight analysis and multiple co-inertia analysis applied to the coupling of several measurement techniques, J. Chemom. 20 (2006) 172-183.

[35] M. Claeys-Bruno, A. Béal, D.N. Rutledge, M. Sergent, Use of the common components and specific weights analysis to interpret supersaturated designs, Chemom. Intelligent Lab. Syst. 152 (2016) 97-106.

[36] P. de B. Harrington, N.E. Vieira, J. Espinoza, J.K. Nien, R. Romero, A.L. Yergey, Analysis of variance-principal component analysis: a soft tool for proteomic discovery, Anal. Chim. Acta 544 (2005) 118-127.

[37] R. Korifi, S. Amat, C. Rebufa, V. Labed, D.N. Rutledge, N. Dupuy, AComDim as a multivariate tool to analyse experimental design application to $\gamma$-irradiated and leached ion exchange resins, Chemom. Intelligent Lab. Syst. 141 (2015) $12-23$.

[38] R.C. Pinto, Development of New Chemometricmethods - Application to the Spectroscopic Characterisation of Food Quality (PhD thesis), AgroParisTech, 2009.

[39] C.B.Y. Cordella, D. Bertrand, SAISIR: a new general chemometric toolbox, Trends Anal. Chem. 54 (2014) 75-82.

[40] M. Anderson, C.Ter Braak, Permutation tests for multi-factorial analysis of variance, J. Stat. Comput. Simul. 73 (2003) 85-113.

[41] G. Mazerolles, J. Boccard, M. Hanafi, S. Rudaz, Analysis of experimental design with multivariate response: a contribution using multiblock techniques, Chemom. Intelligent Lab. Syst. 106 (2011) 65-72.

[42] A. Tidjani, Y. Watanabe, Gamma-oxidation of linear low density polyethylenes: the dose-rate effect of irradiation on chemical and physical modifications, J. Polym. Sci. part A-polymer Chem. 33 (1995) 1455-1460.

[43] J. Lacoste, D.J. Carlsson, Gamma-, photo-, and thermally-initiated oxidation of linear low density polyethylene: a quantitative comparison of oxidation products, J. Polym. Sci. part A-polymer Chem. 30 (1992) 493-500.

[44] Z. Liu, S. Chen, J. Zhang, Photodegradation of ethyleneeoctene copolymers with different octene contents, Polym. Degrad. Stab. 96 (2011) 1961-1972.

[45] R.P. Wool, R.S. Bretzlaff, Infrared and Raman spectroscopy of stressed polyethylene, J. Polym. Sci. Part B-Polymer Phys. 24 (1986) 1039-1066.

[46] G. Socrates, Infrared and Raman characteristic group frequencies, 3rd Edition, p268.

[47] A. Tidjani, R. Arnaud, Gamma-oxidation of linear low density polyethylenes: ethylene-butene and ethylene-hexene copolymers, J. Polym. Sci. Part APolymer Chem. 31 (1993) 603-609.

[48] L.H. Cross, R.B. Richards, H.A. Willis, The infra-red spectrum of ethylene polymers, Discuss. Faraday Soc. 9 (1950) 235-245.

[49] F.J. Boerio, S. Wirasate, in: Neil J. Everall, John M. Chalmers, Peter R. Griffiths (Eds.), Measurements of the Chemical Characteristics of Polymers and Rubbers by Vibrational Spectroscopy, in Vibrational Spectroscopy of Polymers: Principles and Practice, John Wiley and Sons, 2007, p. 114.

[50] G. Socrates, Infrared and Raman characteristic group frequencies, 3rd Edition, p125.

[51] H. Lobo, J.V. Bonilla, Handbook of Plastics Analysis, 2003, pp. 218-220.

[52] G. Socrates, Infrared and Raman characteristic group frequencies, 3rd Edition, p132.

[53] M. Giurginca, L. Popa, T. Zaharescu, Thermo-oxidative degradation and radioprocessing of ethylene vinyl acetate elastomers, Polym. Degrad. Stab. 82 (2003) 463-466.

[54] I. Ishigaki, F. Yoshii, Radiation effects on polymer materials in radiation sterilization of medical supplies, Radiat. Phys. Chem. 39 (1992) 527-533.

[55] K.A. Da Silva Aquino, in: Feriz Adrovic (Ed.), Sterilization by Gamma 
Irradiation, InTech, 2012, ISBN 978-953-51-0316-5. Available from: http:// www.intechopen.com/books/gammaradiation/sterilization-by-gamma-

irradiation.

[56] G. Zerbi, G. Gallino, Structural depth profiling in polyethylene films by multiple internal reflection infra-red spectroscopy, Polymer 30 (1989) 2324-2327.

[57] P. Pagès, Characterization of polymer materials using FT-IR and DSC techniques, Therm. Analysis. Fundam. Appl. Material Charact. (2005) 121-140, 84-9749-100-9.

[58] IR spectrum obtained from webbook NIST database, trans-2-Butene (CAS n 624-64-6).

[59] The incorrect positioning of the $\mathrm{T} 1 \mathrm{~m}$ and $\mathrm{T} 2 \mathrm{~m}$ groups (Fig. $5 \mathrm{f}$ )) are also observed for other batches. 